\title{
IFRS* Phase II and Solvency II: Key Issues, Current Debates
}

\author{
Denis Duverne and Jacques Le Douit \\ AXA, Avenue Matignon 25, Paris 75008, France. \\ E-mails: denis.duverne@axa.com, jacques.LEDOUIT@axa.com
}

The paper discusses key issues and reflects the current debates around two important regulatory projects: Solvency II and International Financial Reporting Standards (IFRS) Phase II. The Solvency II project is based on an economic balance sheet and proposes an economic valuation of insurance liabilities that is very close to the European industry position on assessment of risks and solvency requirements based on how the business is managed. One key element is still under debate: diversification across portfolios. The industry considers that the entity's own diversification must be reflected in the valuation of the insurance liabilities while the Committee of European Insurance and Occupational Pensions Supervisors' has referred to an empty undertaking. IFRS Phase II can appear to be an approach similar to Solvency II, but actually is based on fundamental flaws, excluding future cash flows, and insurers actions, referring to a theoretical market participant efficiency instead of the entity's specific data for expenses, unbundling artificially insurance and financial components, taking into account insurer's own credit standing and adding a service margin to the risk margin. The diverging timetables of IFRS and Solvency II lead to a risk that IFRS and solvency could be non-aligned and increase the danger that IFRS for insurance may be distant from the economics of the business. A consensus within the industry is therefore crucial to facilitate the progress of the international standard for insurance accounting, which would give a true and fair presentation of the economics of the business.

The Geneva Papers (2009) 34, 47-55. doi:10.1057/gpp.2008.42

Keywords: current exit value; market consistent fulfilment cost; contract fulfilment value; profit recognition; diversification

\section{Solvency II: towards an economic approach reflecting the way the business is managed}

The Insurance Framework Directive, ${ }^{1}$ which is expected to be voted on by the end of 2008 defines a new European solvency regime "Solvency II". The proposal is very close to the European industry position on assessment of risks and solvency requirements.

The European industry through its leading organisations, Comité Européen des Assurances (CEA), Chief Financial Officers (CFOs) Forum and Chief Risk Officers

\footnotetext{
* International Financial Reporting Standards.

${ }^{1}$ Framework Directive draft July 2007.
} 
(CROs) Forum speaking with one voice, has been aligned in order to develop a new, economically sound, European solvency regime.

The unanimous view of European insurers is that Solvency II must be based on how the business is managed. This means that the new regime should be based on the management's organisation and tools that have been developed by the industry over the past few years. Major improvements have been made in several key areas such as the pricing of contracts, probability weighted expected future cash flows, pooling of risks, using stochastic techniques and an approach consistent with financial markets assumptions. Solvency II must take advantage of this progress.

The Solvency II Pillar $1^{2}$ is based on an economic balance sheet and proposes an economic valuation of insurance liabilities based on the following features:

- a market consistent approach using market financial assumptions (e.g. discount rate, risk free rate);

- for hedgeable risks, insurance liabilities are measured on the basis of the replicating instrument market price;

- for unhedgeable risks, a market consistent valuation of insurance liabilities is based on

○ portfolio assumptions (e.g. mortality, longevity, claims occurrence ...);

○ entity specific data for other assumptions (claims management, expenses);

- expected future cash in and cash out flows taking into consideration policyholder behaviours;

- risk margin calibrated to the cost of capital method. ${ }^{3}$

\section{Diversification across portfolios: a key issue not yet solved}

There is one key liability measurement issue for unhedgeable risks still under discussion: the diversification of risks across portfolios as one of the key elements of the pooling and mitigation of insurance risk management.

The draft Framework Directive does not include any specific provision with respect to the diversification of risks across portfolios, but it does not preclude taking into consideration diversification benefit. That point should be addressed later in 2009 in the level 2 implementation measures to be taken by the European Commission (Lamfalussy process).

However, the technical specifications for Quantitative Impact Study 4 (QIS 4) have been based on no diversification benefit. This follows the Committee of European Insurance and Occupational Pensions Supervisors' (CEIOPS) view expressed in its background paper, ${ }^{4}$ which has proposed to refer to a reference undertaking, not the undertaking itself but a theoretical undertaking that would be an empty undertaking.

\footnotetext{
${ }^{2}$ Solvency II has three pillars: Pillar 1 quantitative requirements, Pillar 2 supervisory activities, and Pillar 3 supervisory reporting and public disclosure.

${ }^{3}$ See the joint submission by the CRO Forum and CEA.

${ }^{4}$ CEIOPS document for the QIS 4 guidance on the definition of the reference entity for the calculation of the cost of capital.
} 
The industry believes that this approach is not economically sound and considers that the entity's own diversification must be reflected in the risk margin, in line with the way the business is managed.

\section{IFRS Phase II: an approach apparently similar to Solvency II but based on fundamental flaws}

The insurance industry worldwide (American, European, Japanese) has been concerned with the International Accounting Standards Board (IASB) approach proposed in the IASB Discussion Paper (DP) "Preliminary Views on Insurance Contracts". 5

The IASB DP is based on the same three building blocks and on market consistency as Solvency II: (i) expected future cash flows, (ii) discounted at risk free rate, plus (iii) a risk margin. The resulting "current exit value" proposed in the IASB DP is similar to some kind of market consistent transfer approach. One could imagine that the International Financial Reporting Standards (IFRS) should lead to the same economic amount of insurance liabilities as Solvency II. However, that is not the case. In fact, the IASB favour a theoretical, legal and formal approach:

- excluding future cash flows based on policyholder behaviour (future premiums) and insurers' actions (future bonuses), if non-enforceable;

- using expenses based on those of theoretical market participants instead of the actual expense experience of the insurer itself;

- unbundling artificially the insurance and financial components of the contracts supplied by insurers;

- taking into account the insurer's own credit standing;

- adding a service margin to the risk margin.

\section{A specific issue for IFRS: profit recognition}

Solvency II aims to assess the position of the insurers and their ability to meet their commitments. This assessment considers the balance sheet; how and when the profit is recognised through the profit and loss $(\mathrm{P} \& \mathrm{~L})$ account is not of interest for this assessment.

Conversely, the recognition of profit is key for accounting purposes: financial statements aim to provide reporting of the performance of the entities over time along with the statement of their position from the end of one period to the next.

First of all, the question of the initial profit margin, that is the difference between expected future cash inflows and cash outflows has been raised. Views are opposed on the existence and the size of this initial profit margin.

IASB assert that the profit arising at inception, will be small or would correspond to other services rendered at inception or to initial costs (assembling portfolios, franchise, brand, etc.) or will occur due to niche markets or other advantageous market position

\footnotetext{
${ }^{5}$ See http://www.iasb.org.
} 
for participants. This view is based on the "current exit value" of the insurance liabilities as proposed in the DP. Actually, a large part of future profits would be included in the insurance liabilities under the components of risk and service margins that the IASB would add to the best estimate of the discounted future cash flows.

The European industry (CEA and CFO Forum) believes that the initial profit is more significant than that envisaged by the IASB. The size of the initial profit margin is demonstrable in market transactions and in published market consistent embedded value figures.

The European industry considers that the insurance liabilities should not include future profits, both for accounting and solvency purposes (for Solvency II, future profits being available capital in Tier 1). Indeed, future profits should be accounted for in a separate item on the balance sheet ("deferred profit") and released through the $\mathrm{P} \& \mathrm{~L}$ when the risk is released (like the risk margin). Alternatively, this deferred profit might be a component of the accounting liability disclosed in the notes to the accounts.

This issue is linked to the current debate on the measurement attribute for insurance liabilities, which opposes current exit approach to settlement or fulfilment approach. In this context, the Group of North American Insurance Enterprises (GNAIE) supports a kind of entry value based on a "contract fulfilment value" approach: the risk margin would be calibrated to the premiums (deemed as only existing market price) and as a result there would be no profit at inception, but the insurance liabilities amount would include all future profits. This position may not be far from the IASB proposal.

Beyond the profit recognition issue, there are several pending issues under debate between insurers: single measurement model vs. dual model including presentation of income statement; measurement attribute; transfer vs. settlement; presentation of income statement; the appropriate rate of interest to be used in discounting cash flows in life insurance.

\section{Single measurement model vs. dual model}

Most of the current frameworks currently use different accounting models to account for Life and Property and Casualty (P\&C). There are some main differences in most of the existing models: life insurance business is recognised on an underwriting year basis while most of the $\mathrm{P} \& \mathrm{C}$ lines (rather than be limited to short term businesses) are recognised on an accident year basis (except for example, construction, transportation, and credit insurance in Europe) leading to unearned premium reserves (UPRs), which are mainly a presentation difference (premium reserves instead of a claim reserve) in a no gain at inception environment (because premium reserves include profit margins). A second difference is the discounting of reserves in the Life business, but not in the P\&C business.

However, both types of the current models share common characteristics such as no gain at issue, locked-in assumptions (unexpired risk periods), except when loss recognition tests bite and no separate disclosures of profit margins and risk margins on the face of the balance sheet or in the notes. 
The CFO Forum supports one single model for life and non-life measurement of policyholders liabilities based on discounting reserves, explicit disclosure of risk (and profit) margins, future cash flows including regular premium for life as such cash flows are part of the initial contract, but no renewals in the P\&C business as these cash flows were not part of the initial contract (same as GNAIE). The CFO Forum notes that Life and $\mathrm{P} \& \mathrm{C}$ have the same business basis: uncertainty about a future event, inverted economic cycle, only different occurrence (statistical) laws and different duration, which do not correspond to IASB identifiable differences. A single model is consistent with pricing methodologies, risk management practices and Solvency II. Furthermore, it is difficult to draw a line between life and non-life contracts using IFRS language: what about health, workers compensation, etc.?

Supporters of a dual model often highlight duration and risks, uncertainty and volatility as being the biggest differences between life and non-life contracts; such differences should be based on the use of the right inputs - namely, differences that reflect the nature of the contractual risks in each class of business - rather than by applying two different models. The CFO Forum proposal is the "Market consistent fulfilment cost" jointly developed with the CRO Forum first for Solvency II purposes, but also for accounting purposes. ${ }^{6}$ This approach is the same as the one retained for Solvency II, but including allowance for diversification benefit based on an entity's own diversification.

The GNAIE is in favour of a different model for $\mathrm{P} \& \mathrm{C}$ without discounting for time value and no explicit risk margin. GNAIE observes that $\mathrm{P} \& \mathrm{C}$ existing frameworks are not broken, so why change them? By contrast with the Life business, for most P\&C businesses, the underlying contracts are less complex (while being more uncertain) and there is considerably less variation in the accounting models in use throughout the world.

The GNAIE has proposed the P\&C "contract fulfilment value", which would utilise a UPR for pre-claims liabilities, that is no gain at issue and no explicit risk or service margin for claims liabilities; there might be discounting only if the cash flows and payment patterns can be reliably determined on an individual claim basis (e.g. workers compensation claims). In contrast, the Life "contract fulfilment value" would utilise the best estimate liabilities discounted with unlocked assumptions (using asset rates) plus an explicit risk margin calibrated to the premiums, so including profit margins (the same "no gain at issue" principle as in the P\&C GNAIE model).

For $\mathrm{P} \& \mathrm{C}$ insurance contracts, the underlying rationale of the GNAIE for supporting the continued use of implicit as opposed to explicit margins is that explicit margins are not calculated, analysed or otherwise used to measure the performance of individual insurance contracts or groups of insurance contracts. Moreover, this information is not calculated or used internally to manage the business or to hold management accountable for business results. GNAIE believes it is important to understand that the reason why explicit risk margins are not calculated for non-life insurance contracts is not that it is too difficult a task but rather is considered too judgmental a process as the insurer, for example, typically has no basis to accurately measure, or more importantly, verify the risk margin for individual non-life insurance

${ }^{6}$ CRO Forum MVL paper. 
contracts or blocks on non-life insurance contracts (no possible reference to market data). With regard to the discounting, the GNAIE believes that unless the amount and timing of the anticipated cash outflows are reliably estimable on an individual claim basis, discounting would not be appropriate as the absence of reliable inputs to any discounted cash flow model would result in the model outputs not being reliable, verifiable, comparable or relevant. In addition, non-life insurance contracts are not implicitly or explicitly interest-bearing and as such GNAIE believes that a discounted presentation would be misleading to financial statement users.

\section{Presentation of income statement}

Linked to the debate on single model vs. dual model, the presentation of the income statement has yet to be further considered: would it be a single presentation based on a "margin analysis" or two models with margin analysis for Life business and traditional presentation for $\mathrm{P} \& \mathrm{C}$ ? That is premiums to be recorded as: revenue vs. deposits. There is still a debate within the industry, and not yet any IASB position. While in favour of margin analysis for Life business, the CFO Forum has not formed its view on this topic for P\&C. The GNAIE has tentatively envisaged that all premiums both for life and non-life insurance would be treated as deposits and then allocated to the P\&L statement depending on the business.

\section{Measurement attribute: transfer approach $(I A S B)$ vs. settlement approach (industry)}

Most commentators of the DP have indicated that the IASB should consider a settlement value approach as a valuable alternative to the current exit value. The IASB has decided to follow this suggestion and resumed its work in September 2008 by an educational session presenting what could be a settlement or fulfilment approach. Choice between the two approaches was planned for December 2008.

In order to contribute to the IASB's reflection, CFO Forum and GNAIE have provided the IASB with more in-depth proposals.

In broad terms, the settlement value consists of the present value of cash flows expected to be paid to fulfil the obligations to policyholders in the ordinary course of business over time ("ultimate settlement") as opposed to the current exit value, which is based on the value that the insurer would have to pay at the balance sheet date to a third party for transferring the obligation.

\section{Exit value vs. entry value, calibration of the margin and day 1 profit}

The CFO Forum proposes an exit value based on the "market consistent fulfilment $\operatorname{cost}^{17}$ (or production cost) with entity or portfolio specific assumptions in absence of market data and including an explicit margin for risk and uncertainty (reflecting the cost of risk). This risk margin is a market value margin covering the cost of bearing the

\footnotetext{
${ }^{7}$ See footnote 6 .
} 
risks and is measured based on the cost of capital method, including only the cost of the required solvency capital and excluding any other compensation. As a result, the future profits are excluded from the insurance liabilities except the compensation included in the risk margin. The residual margin, that is the excess of the premiums on the insurance liabilities corresponds to the day 1 profit. The CFO Forum proposes that this initial profit be booked as deferred profit in a separate element of liability in the balance sheet and released over time through P\&L.

The GNAIE supports an entry value based on the contract fulfilment value with entity or portfolio specific assumptions like the CFO Forum proposal, but with calibration of the risk margin to the premiums; this means that the profit margin would be included in the liabilities. The GNAIE considers that the only relevant market is the retail market and premiums are the only observable market prices.

This debate comes from different backgrounds and different objectives:

For North American insurers, there are several set of accounts for different purposes: financial information for general purpose, which includes tax and legal (dividends ...) constraints but independent from solvency reporting. As a consequence, there is no incentive for U.S. insurers to make proposals for solvency.

On the other hand, European insurers have to take into consideration the fact that the Solvency II project is based on IFRS for measuring the economic balance sheet with few if any adjustments. Conversely, IFRS accounts are independent from tax and legal considerations. In this context, it is obvious that European insurers have to elaborate on a consistent framework for measuring insurance liabilities both for IFRS and Solvency II.

\section{What rate for discounting life insurance cash flows?}

The CFO Forum supports market risk free rate consistently with pricing of contracts and proposes to refer to the swap rate. Amid various arguments, one notes that the swap yield curve is the reference curve at which options are traded and quoted in most markets, and swaps are more liquid than government bonds and thus provide for more reliable valuations. ${ }^{8}$

The GNAIE and Japanese life insurers are in favour of expected return rate on assets. Otherwise, a risk free rate would trigger accounting losses at inception for some profitable contracts priced on expected return basis.

However, the discounting at risk free rate (the swap rate) supported by the CFO Forum and the discounting at rate of return on investments after an allowance for credit risk as proposed by the GNAIE, could lead to a small difference.

\section{What should be done? Next steps}

Insurers are facing a huge challenge: they must respond to the concerns of the investors. Accounting for insurance has been a "black box" for a very long time.

\footnotetext{
${ }^{8}$ MCEV (June 2008).
} 
It is still perceived like that despite the efforts made by insurers and the implicit assumption that IFRS should have provided better comparable and understandable information.

The danger is that investors turn away from insurance (which represents only 4 per cent of financial capital markets). If insurers are not able to make joint proposals together, the consequence will be a persistent high discount on share prices compared to other industries.

The insurance industry needs to act together worldwide in order to reach a common position on IFRS and to have a realistic chance of influencing the IASB.

Following The Geneva Association "Roundtable on IFRS and Solvency Issues" in New York, 13 May 2008, the decision has been taken at their General Assembly in May 2008 that The Geneva Association would engage the challenge of helping to resolve the significant differences remaining within the industry on the issues of insurance accounting.

As follow up to this decision, an IFRS 1 Stage Roundtable was organised in September 2008 with the CFO Forum, the CRO Forum, and the GNAIE. Japanese life insurers were represented in this roundtable. Three topics were addressed:

(i) Life vs. P\&C (single vs. dual model, discounting and financial statement presentation),

(ii) profit margin as an explicit or implicit component of the liability (accounting), and

(iii) discount rate/risk margin.

There are other themes to be addressed later. For instance:

- solvency issues: time horizon; confidence level and cost of capital;

- accounting issues: reporting of the changes in the value of assets and liabilities and volatility of earnings;

- how to reconcile market consistent economic valuation in the balance sheet and a performance reporting not polluted by the short term "noise" of financial markets: use of Other Comprehensive Income and reconsideration of classification of assets, including held-to-maturity approach;

- cross-sectional theme on accounting and solvency;

- valuation of liabilities; use of market information (mark-to-market approach and the shortcomings of this methodology), hedging/non-hedging of portfolios, discount rate.

While it is too early to predict the outcome of such discussions, it is now clear that they allow a better mutual understanding of concerns on each side, and progress towards a consensus is not out of sight.

\section{IFRS Phase II and Solvency II: different timetables, different outcomes?}

\section{Solvency II}

The Insurance Framework Directive should be completed by the end of 2008 . Implementation measures are expected by 2010 and implementation is planned for 2012. 


\section{IFRS Phase II}

The IASB Phase II insurance contract project is not part of the Memorandum of Understanding (MoU) between the IASB and the Financial Accounting Standards Board. In the context of the convergence and the roadmap of the Securities and Exchange Commission for application of IFRS by U.S. listed companies, the objective of this MoU is to develop a stable platform by 2011 for application by 2013 . That means that most of the resources of the IASB are concentrated on the convergence projects. Even if the hypothesis of a postponement of the insurance project has been rejected by the chairman of the IASB, there is still a risk that the insurance contract project would be delayed after completion of their other structuring projects such as revenue recognition, measurement, definition of assets and liabilities, presentation of financial statements, etc. In such a scenario, the risk is that IFRS Phase II be developed as implementation guidance for insurance of general standards instead of a specific accounting for insurance standard.

According to the IASB draft work plan for IFRS Phase II, the Exposure Draft would be issued by the end of 2009. But there is still significant uncertainty as far as the target date for final standard issuance, which is not expected before the end of 2011 or 2012 (with a first application 2 years later, i.e. in 2013 or 2014).

\section{Conclusion}

The diverging timetables of IFRS and Solvency II lead to the risk that IFRS and solvency could be non-aligned and increase the danger that IFRS for insurance may be distant from the economics of the business. A consensus within the industry is therefore crucial to facilitate the progress of the international standard for insurance accounting, which would give a true and fair presentation of the economics of the business.

\section{References}

CEIOPS-DOC-09/2008, (1 April 2008).

CRO Forum and CEA (2006) Solutions to Major Issues for Solvency II (7 February).

CRO Forum MVL paper. Market Value of Liabilities for Insurance Firms: Implementing Elements for Solvency II', www.croforum.org.

MCEV (2008) 'Market Consistent Embedded Value Basis for Conclusions', (June) http://www.cfoforum.nl/ eev.html.

\section{About the Authors}

Denis Duverne is a member of AXA's Management Board, CFO, and is the current chairman of the CFO Forum. The CFO Forum is a high-level discussion group formed and attended by the CFOs of major European insurance companies. Its aim is to discuss issues relating to financial reporting developments for their businesses and how they can create greater transparency for investors.

Jacques Le Douit is Chairman of the Accounting Committee of the French Insurance Association (FFSA), Chairman of the Accounts Committee of the CEA, and a member of EFRAG Insurance Accounting Working Group (previously Insurance Sub Committee). 